\title{
Prototype Mesin Pencarian Pada Presensi Perkuliahan Menggunakan Semantic Web
}

\author{
Lestari Retnawati $^{1)}$, Nia Saurina ${ }^{2)}$ \\ ${ }^{1,2)}$ Prodi Teknik Informatika, Fakultas Teknik, Universitas Wijaya Kusuma Surabaya \\ Email: ${ }^{11}$ lestari.047@gmail.com ${ }^{2)}$ niasaurina@gmail.com
}

(naskah masuk: 28 Desemeber 2018, diterima untuk diterbitkan: 20 Januari 2019)

\begin{abstract}
ABSTRAK
Presensi merupakan proses pengumpulan data guna mengetahui kehadiran seseorang dalam suatu kegiatan. Salah satu kegiatan yang membutuhkan presensi adalah perkuliahan. Presensi dalam perkuliahan secara umum masih dilakukan secara manual, yakni dengan menggunakan lembar presensi yang dibawa oleh dosen di tiap pertemuan.

Tujuan penelitian ini adalah untuk melakukan pengembangan sistem pencarian dengan memanfaatkan teknologi web semantik sehingga dapat menjadi alternatif untuk menggantikan pencarian data berdasarkan presensi manual.

Dalam penulisan ini komponen-komponen teknologi web semantik yang dipergunakan adalah RDF (Resource Description Framework) sebagai representasi pengetahuan yang digunakan. Komponen yang kedua adalah SPARQL digunakan untuk mengambil informasi yang terdapat pada RDF. Komponen yang terakhir adalah RAP (RDF API for PHP) yang dipergunakan untuk menjembatani antara RDF dengan PHP sehingga informasi yang ada di dalam RDF dapat digunakan pada PHP. Aplikasi ini dirancang untuk menghasilkan keluaran yang mudah dimengerti oleh pemakai serta membantu dalam pencarian presensi perkuliahan. Setelah sistem pencarian penelitian ini di uji coba, menunjukan bahwa sistem pencarian dapat menghasilkan keluaran yang mudah dimengerti oleh pengguna namun pada kemudahan penggunaan masih dirasa kurang. Dikarenakan masih kurangnya fasilitas untuk mempermudah pencarian presensi perkuliahan.
\end{abstract}

Kata Kunci: presensi perkuliahan, semantic web, RDF.

\begin{abstract}
Presence is the process of gathering data to find someone in an activity. One of the activities that requires attendance is lectures. Presence in lectures is still done manually, namely by using attendance sheets conducted by lecturers at each class.

The purpose of this research is to develop a system to search using semantic web technology so that it can be an alternative for data search assistance based on manuals.

In this context the semantic web technology components used are RDF (Resource Description Framework) as a representation of the knowledge used. The second component, SPARQL, is used to retrieve information carried out on RDF. The last component is RAP (RDF API for PHP) which is used to bridge between RDF and PHP so that the information contained in RDF can be used in PHP. This application is designed to get results that are easily understood by users and also helps in finding the presence of lectures. After this research search system is tested, it shows that the system could search and produce information that is easily understood by users, but the ease of use is still lacking. Because it still requires facilities to search for lecture presence.
\end{abstract}

Keywords: lecture presence, semantic web, RDF. 


\section{PENDAHULUAN}

World Wide Web adalah gudang informasi terbesar berisi dokumen dan database tentang hampir setiap subjek yang bisa dibayangkan, dan semua data ini tersedia secara instan untuk siapa saja yang memiliki koneksi internet. Sebuah halaman web dihosting oleh banyak komputer, di mana setiap dokumen dapat menunjuk ke dokumen yang lain, baik di komputer yang sama atau berbeda. Sehingga semua orang di seluruh dunia dapat menyediakan konten di Web, yang memungkinkannya tumbuh secara eksponensial serta membuat banyak orang belajar bagaimana menggunakannya untuk berbagi informasi melalui web (Pavel, 2013).

Istilah semantik data mengacu pada data yang memiliki makna dan dibuat secara eksplisit dalam bentuk meta-data. Metadata kemudian dapat digunakan dengan pendekatan berbasis semantik untuk mengelola data. Metode yang paling umum untuk mewakili data semantik dan meta-datanya didasarkan pada Resource Description Framework (RDF) (Rahm, 2001) dan keluarga dari standar terkait yang diusulkan oleh World Wide Web Consortium (W3C), misalnya SPARQL, RDFS dan OWL. Saat ini, standar-standar ini digunakan untuk berbagai implementasi perangkat lunak yang mendukungnya dan dianggap cukup matang sebagai dasar penerapan teknologi semantik di berbagai bidang. Contohnya seperti pembuatan ValCri (analitik visual untuk pembuatan semantik di bidang kepolisian) (Santodomingo, 2014), pengelolaan jaringan air minum melalui gelombang elektromagnetik (Bikakis, 2016), dan pengelolaan pelayanan di bidang kebudayaan secara grafis di Perancis (Abedjan, 2015).
Salah satu perkembangan teknologi yang digunakan pada semantic web adalah ontology. Ontology biasanya menyediakan kosakata yang menggambarkan domain tertentu dan spesifikasi istilah makna dari kosakata tersebut (Mohammad, 2010). Ontology digunakan untuk melakukan pencarian pada heteroginitas data (misalkan data presensi perkuliahan bercampur dengan data akademik dan data keuangan), permasalahan yang sering muncul saat melakukan pencarian di presensi perkuliahan adalah hasil presensi tidak sesuai dengan yang diinginkan. Beragam mesin pencari terus bersaing untuk memenuhi kebutuhan masyarakat akan perolehan informasi secara tepat dan cepat (Biffl, 2016). Cara yang dapat digunakan untuk mengurangi permasalahan yang timbul pada presensi perkuliahan yang tersimpan sebagai heteroginitas data, adalah dengan Ontology Matching yang membandingkan dua buah ontology seputar presensi perkuliahan (misalkan data kehadiran mahasiswa) dan menemukan keterhubungan diantara kedua ontology tersebut. Ada beberapa teknik yang menggunakan ontology matching dalam menyelesaikan permasalahan heterogenitas data diantaranya adalah teknik berdasarkan terminology, teknik berdasarkan struktur, dan teknik berdasarkan konten. Teknik berdasarkan terminology merupakan salah satu teknik ontology matching yang dapat digunakan dalam menyelesaikan permasalahan pada penelitian ini. Teknik terminology ini menggunakan data leksikal dari konsep yang terdapat pada ontology untuk mencocokan konsep dengan cara membandingkan string, dengan menambahkan data tambahan (additional inputs) dan instances (Abadi, 2009). 


\section{METODE PENELITIAN}

Secara umum, tahapan pada penelitian ini dapat dilihat pada gambar 2 .

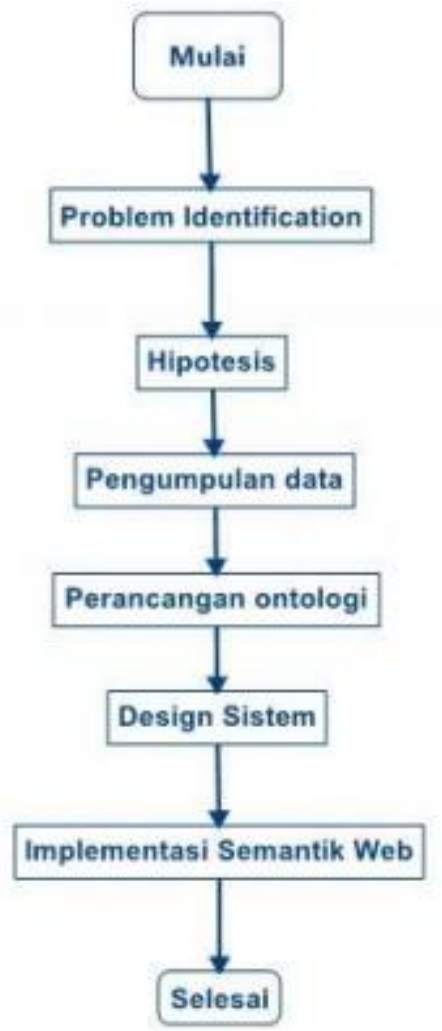

Gambar 2. Metode Penelitian

Gambar 2 merupakan tahapan dalam melakukan penelitian, berikut penjelasan dari tahapan-tahapan tersebut

1. Identifikasi pada permasalahan, pada tahapan ini dilakukan identifikasi terhadap permasalahan yang terjadi, permasalahan yang mendorong dilakukannya penelitian pada domain penelitian.

2. Hipotesis, tahapan ini menentukan hipotesis awal yaitu web semantik dapat diterapkan pada domain learning resource untuk mempermudah pencarian.

3. Pengumpulan data, pengumpulan data terkait dengan domain learning resource.

4. Perancangan Ontologi, pada tahap ini dilakukan perancangan ontologi berdasarkan hasil pengumpulan data yang telah dilakukan.

5. Perancangan pada Sistem, pada tahap ini dilakukan perancangan antarmuka sistem.

6. Implementasi, tahapan selanjutnya adalah mengimplementasikan ontologi dan perancangan antarmuka menjadi web semantik.

Adapun alat dan bahan yang digunakan antara lain:

1. Data learning resource

2. Protégé

3. RDF Api

4. Laptop/PC

\section{PERANCANGAN DAN PENGUJIAN}

\subsection{Perancangan Ontology}

Untuk melakukan pengembangan mesin pencarian pada repositori koleksi presensi perkuliahan menggunakan teknologi web semantik maka diperlukan sebuah ontologi yang dapat merepresentasikan pengetahuan apa saja yang diperlukan dalam membangun mesin pencarian tersebut. Dalam penelitian ini, ontologi diberi nama "domain learning resource". Pada tahapan ini maka peneliti melakukan perancangan ontology dengan dibantu software protégé. Hasil dari perancangan ontologi dapat dilihat pada tabel 1, dan tabel 2 .

Tabel 1. Class, SubClassOf

\begin{tabular}{cc}
\hline class & SubclassOf \\
\hline Jenis & Thing \\
\hline Katagori & Thing \\
\hline Lecturer & Thing \\
\hline Matakuliah & Thing \\
\hline Materi & Thing \\
\hline
\end{tabular}

Tabel 2. Object Property

\begin{tabular}{ccc}
\hline $\begin{array}{c}\text { Oject } \\
\text { Property }\end{array}$ & Domain & Range \\
\hline Create & Lecture & Materi \\
\hline Has & Materi & Lecture \\
Author & & \\
\hline
\end{tabular}




\begin{tabular}{ccc}
\hline Has Jenis & Materi & Jenis \\
\hline $\begin{array}{c}\text { Has } \\
\text { Katagori }\end{array}$ & Materi & Katagori \\
\hline Has Materi & Matakuliah & Materi \\
\hline Teach & Lecture & Matakuliah \\
\hline
\end{tabular}

\subsection{Perancangan RDF}

Setelah ontologi dirancang, selanjutnya adalah memasukkannya ke dalam RDF data store, yaitu database MySQL, dimana mesin pencarian dapat memperoleh bentuk RDF database, prefix, namespace, dan dapat dilakukan simulasi query SPARQL di dalamnya. Tersedia 2 (dua) cara untuk memasukkan data OWL/RDF ke dalam data MySQL OWL/RDF, yaitu melalui command line atau melalui kode aplikasi PHP.

\subsection{Perancangan Query}

Pada tahapan ini peneliti melakukan perancangan query yang terdiri dari 3 (tiga) jenis, yaitu perancangan query untuk pencarian berdasarkan kata kunci, query untuk pencarian berdasarkan pencarian simple, dan query untuk pencarian advanced.

\subsection{Pengujian Sistem}

Pada tahapan ini peneliti melakukan pengujian mesin pencarian yang dilakukan untuk mengetahui nilai performansi dan tingkat kemiripan dari dua buah ontology yang ada pada sistem yang mencari keterhubungan ontology pada web semantic dengan menggunakan metode Semantic-based Ontology Matching. Pengujian ini dilakukan dengan 3 buah data yang berekstensi * .owl dan dua buah data yang berekstensi * ${ }^{*}$.rdf. Dari semua file ontologi tersebut kemudian dicari keterhubugannya adalah dua buah data ontologi dan satu data reference. Dapat dikatakan bahwa dalam pengujian ini dilakukan dua percobaan dengan data yang berbeda, yang nantinya akan dilihat perbedaan pengaruh dari keterhubungan dua pasangan data tersebut. Pada penelitian ini ada dua jenis pengujian yang dilakukan. Pengujian untuk mencocokkan dua buah file ontology dilakukan dengan melakukan dua kali percobaan yang menggunakan sepasang file ontology dengan format *.owl yaitu antara "presensi1.owl" dan "presensi2.owl", dan satu percobaan berikutnya antara ontology "presensi1.owl" dan "presensi2.owl", digunakan untuk mencari korespondensi antar pasangan data ontology tersebut. serta menginputkan satu file ontology lain dengan format *.rdf pada setiap percobaan, yang bernama "ref.rdf" yang dipakai untuk mendapatkan nilai evaluasi dengan tingkat precision yang berbeda, recall atau pemanggilan ulang objek, dan f-measure serta untuk mendapatkan ontology alignment yang baru. Proses pencocokan dua buah ontology ini dilakukan dengan diberikan parameter Similarity Threshold tertentu pada program yang dibuat.

\subsection{Generate RDF}

Generate RDF Untuk menguji apakah dokumen XHTML tersebut bisa ditransformasikan oleh dokumen XSL sesuai dengan yang diharapkan maka dibutuhkan sebuah bahasa pemrograman yang bisa menjalankan proses ekstraksi kedua dokumen tersebut secara paralel. Adapun bahasa pemrograman yang digunakan pada penelitian ini menggunakan PHP. Untuk menggenerate dokumen RDF dibutuhkan sebuah perintah spesifik pada bahasa pemrograman PHP yaitu XSL Processor. Dengan menggunakan perintah XSL Processor web server akan menjalakan perintah untuk melakukan transformasi data dari halaman XHTML kedalam format dokumen RDF 
dalam bentuk XML. Adapun perintah yang digunakan untuk menggenerate dokumen ini hampir sama antara halaman daftar specimen dan de-tail specimen, perbedaannya hanya terda-pat pada link halamannya. Script yang digunakan untuk menggenerate dokumen RDF pada halaman XHTML detail specimen Blok program merupakan sebuah fungsi dengan 1 parameter yaitu specimenid. Parameter ini digunakan oleh perintah selanjutnya untuk menunjuk halaman XHTML dari specimen tersebut seperti yang ditunjukan oleh variabel urIData. Halaman specimen tersebut kemudian di load dengan menggunakan fungsi PHP DOMDocument. Perintah selanjutnya adalah mengimport file XSL yang sudah dibuat sebelumnya untuk bisa diproses bersamaan dengan dokumen XHTML. Setelah kedua dokumen tersebut berhasil di load langkah selanjutnya adalah melakukan proses transformasi dengan mengeksekusi perintah \$xsit>transform ToXML $(\$ X M L)$ maka proses ekstrak data dari halaman XHTML yang disesuaikan dengan template XSL akan dieksekusi. Hasil dari perintah tersebut akan menghasilkan dokumen RDF seperti yang terlihat pada gambar 3 . Terlihat bahwa sebuah file RDF sudah terbentuk setelah melewati proses ekstraksi data dengan menggunakan pemrograman PHP, format dokumen inilah yang menjadi tujuan dari penelitian ini. Pada dokumen tersebut terdapat judul dokumen hingga dengan data dari specimen yang berhasil diekstrak yang dibedakan berdasarkan tag description.

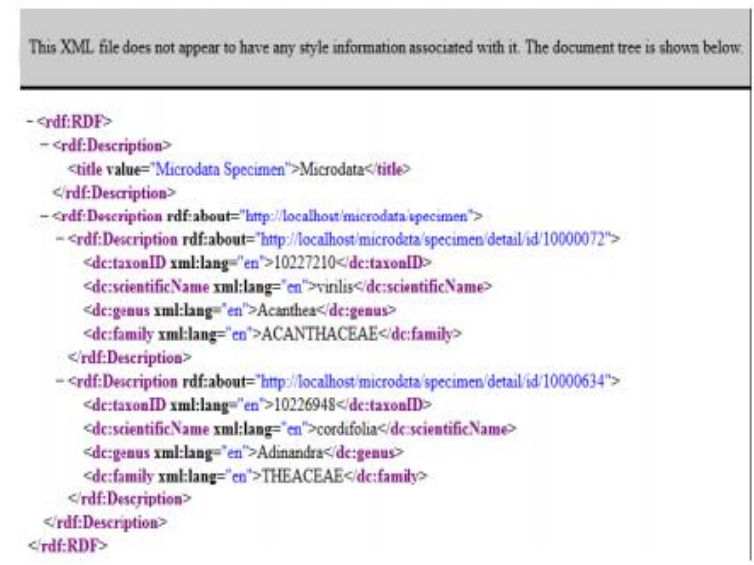

Gambar 3. Generate RDF

\section{KESIMPULAN DAN SARAN}

Penelitian ini membahas mengenai perancangan ontologi pada presensi perkuliahan sehingga dapat memanajemen data presensi dengan baik dengan memanfaatkan fitur web semantik. Penelitian selanjutnya diharapkan dapat dengan mengembangkan domain-domain yang ada, sehingga sistem dapat diintegrasikan dengan sistem lainnya.

\section{DAFTAR PUSTAKA}

Pavel, S.; Euzenat, J. Ontology matching: state of the art and future. IEEE Transactions On Knowledge And Data Engineering, VOL. 25, ISSUE: 1, January 2013, pp.158-pp.176.

Rahm, E.; Bernstein, P. A. A survey of approaches to automatic schema matching. The VLDB Journal 10,Digital Object Identifier (DOI) 10.1007/s007780100057 2001, 334-350.

Santodomingo, R.; Rohjans, S.; Uslar, M.; Rodríguez-Mondéjar, J. A.; SanzBobi, M. A. Ontology matching system for future energy smartgrids. Engineering Applications of Artificial Intelligence 2014, 242-257.

Eko Budi Setiawan, Bobi Kurniawan, 2015.

Perancangan Sistem Absensi

Kehadiran Perkuliahan dengan 
Menggunakan Radio Frequency Identification (RFID). Jurnal CorelT, Vol.1, No.2, Desember 2015 ISSN: 2460-738X

Abdulloh Fakih, Indra Kharisma Raharjana, Badrus Zaman. 2015. Pemanfaatan Teknologi Fingerprint Authentication untuk Otomatisasi Presensi Perkuliahan. Journal of Information Systems Engineering and Business Intelligence Vol. 1, No. 2, October 2015

D. Nandini, Semantic Web And Ontology, Bookboon, 2014.

Euzenat, J., Shvaiko, P. 2007. Ontology Matching. Berlin Heidelberg: Springer- Verlag.

D. J. Abadi, A. Marcus, S. Madden, and K. Hollenbach, "SW-Store: A Vertically Partitioned DBMS for Semantic Web Data Management," VLDB Journal, 18(2), pp. 385-406, 2009.

Mohammad Mustafa Taye, "Understanding Semantic Web and Ontologies: Theory and Applications," Journal of Computing, vol. 2, no. 6, 2010.

Julien Wollbrett et. al., "Clever generation of rich SPARQL queries from annotated relational schema: application to Semantic Web Service creation for biological databases", BMC Bioinformatics, 2013.

María Taboada, Diego Martínez, Belén Pilo, et.al, "Querying phenotypegenotype relationships on patient datasets using semantic web technology: the example of cerebrotendinous xanthomatosis", BMC Medical informatics \& Decision Making, 2012.

Z. Abedjan, T. Grutze, A. Jentzsch, and F. Naumann. " Profiling and mining RDF data with ProLOD++," In Proceedings of the IEEE 30th International Conference on Data Engineering (ICDE), pp 1198-1201, 2014.

N. Bikakis and T. K. Sellis,"Exploration and Visualization in the Web of Big Linked Data: A Survey of the State of the Art," In Proceedings of the Workshops of the EDBT/ICDT 2016 Joint Conference, pp. 128-133, 2016.

Shareha, Ahmad., Rajeswari, M., Ramachandram, D. "Two-way Dictionary-based Lexical Ontology Alignment". Singapore: International Conference on Computer Engineering and Aplication, 2009.

S. Biffl and M. Sabou, Semantic Web Technologies for Intelligent Engineering Applications, Springer, 2016.

O. Cur'e and G. Blin., RDF Database Systems: Triples Storage and SPARQL Query Processing. Morgan Kaufmann Publishers Inc., San Francisco, CA, USA, 1st edition, 2014.

Cowie, A.P. Semantics. Oxford: Oxford University Press. 2009. 